\title{
Dynamic size constancy
}

\author{
LEONARD BROSGOLE, DANIEL G. McNICHOL, ðOHN DOYLE, and ANN NEYLON \\ St. John's University, Jamaica, New York 11439
}

\begin{abstract}
A nulling procedure was used to estimate the size of a stimulus which moved back and forth in depth from a distance of 5 to $30 \mathrm{ft}$ from the observer. This was compared to a condition where the target was positioned statically from 5 to $30 \mathrm{ft}$ away, with size estimates made by varying a comparison stimulus. Both conditions were run with monocular and binocular viewing. For static presentation, constancy was maintained throughout with binocular vision, but it finally broke down monocularly at a $30-\mathrm{ft}$ viewing distance. For the dynamic presentation, there was a pronounced regression toward visual angle under both binocular and monocular observation. The basis for this unanticipated finding was fully discussed.
\end{abstract}

Although the invariance hypothesis has been attributed to Holway and Boring (1941), it has served as the primary conceptual model in explaining size constancy throughout the history of perception. On the one hand, Koffka (1935) pointed out that there is a cognitively assumed invariant relationship between size and distance which permits size change to be used as a cue to distance and distance change as a cue to size. On the other hand, Boring (1943) proposed that the interaction between optical size and distance is an unconscious, habituated, perceptual response. While Gibson (1952) maintained that the reciprocity between size and distance is given directly in the optical array, Boring (1952) insisted that this must be preceded by the assumption that objects cannot vary in their physical properties as a result of distance change. Brosgole (1968) interpreted this notion of assumed physical invariance as a direct perceptual effect, falling under the category of "phenomenal identity." Regardless of how it has been interpreted, then, one can readily see that invariance emerges as the principal explanation of size constancy. It would follow logically that size constancy should be enhanced by any condition which facilitates perceptual invariance.

It would seem plausible to assume that observing a visual target in motion should promote a sense of phenomenal identity, as well as revealing the invariance of size to distance in immediate experience. Therefore, size constancy should fare better with dynamic observation, compared to the traditional method of presenting stimuli statically. This may be expected even under impoverished conditions (e.g., monocular viewing), as movement itself into the third dimension can serve as a cue to distance by virtue of the changes generated in angular velocity of the target. Accordingly, the following experiments were designed to compare size estimates rendered during dynamic and static stimulus presentation.

\section{EXPERIMENT I}

This study assessed whether the size of a moving target is perceived with the same constancy as one which is positioned statically at varying distances from the observer. Accordingly, size estimates were obtained with binocular viewing under conditions of dynamic and static stimulus presentation.

\section{Method}

The subject was seated in total darkness at the intersection of an L-shaped chamber. He sat on a swivel chair in front of a Bausch and Lomb instrument table with head fixed in place in a Bausch and Lomb chin rest. Both the chair and instrument table rested on a platform $3 \mathrm{ft}$ above the floor. When positioned in the chin rest, the subject faced the long alley of the chamber with its far wall $32 \mathrm{ft}$ away. When swiveling to the right, the subject looked down the short arm of the "L" with its far wall $10 \mathrm{ft}$ away. A lighted control room, containing support equipment, adjoined the dark room. An intercom system enabled voice communication between the two areas.

There were two conditions. Subjects looked down the long arm of the " $L$ " in Condition 1 to see two vertically aligned sperical targets. The targets measured $1 \frac{1 / 2}{2}$. in diam and were illuminated, so as to be barely discriminable in darkness. The stimuli were made of ping pong balls with a standard $12-\mathrm{V} \mathrm{dc}$ lamp mounted inside. Brightness was controlled by a variable dc supply. The stimuli were positioned symmetrically with reference to the nasion and were separated by $6 \mathrm{deg}$ in total. They moved toward and away from the observer at a rate of $6 \mathrm{in} . / \mathrm{sec}$, covering a distance of from 5 to $30 \mathrm{ft}$. The targets were housed on a motorized frame that rode back and forth along a track that was mounted to the ceiling of the dark room. Movement of the frame was recorded on a Beckman Type $\mathbf{R}$ dynograph. The observer was advised to take note of how far apart these targets appeared to be in their starting position. Once the stimuli were set into motion, the subject's task was to keep the distarice between them constant by rotating a control knob located on the instrument table. (The housing for the targets consisted of two vertically aligned pulleys, one of which was fixed to the shaft of a synchronous motor. The stimuli were fastened to the opposite ends of a belt that joined the pulleys. Thus, rotation of the control knob turned the motor, thereby effecting a symmetrical distance change between the stimuli. This, too, was recorded on the dynograph.) So, for example, if they appeared to come together by virtue of their movement away from the observer, the subject was to separate them further by turning the control knob appropriately. Conversely, the subject was required to decrease the separation if the stimuli seemed to depart, presumably as they approached him. Thus, the constancy of the phenomenal linear extent between the targets was assessed dynamically through such a compensatory tracking procedure. 
The subject was told that he would be participating in a study of how people judge size and that size would be represented by the amount of separation between two visual stimuli. He was informed that the stimuli would move toward and away from him and that the separation might appear to change as a function of distance. The subject was advised that the space between the targets was, in fact, constant and that any change noted was purely perceptual. He was, however, asked to respond in terms of what he honestly saw, as opposed to what he knew of the situation, and was shown how to manipulate the targets by using the control knob. It was feared that the equipment would give away the experiment, i.e., that the subject might come to realize that an apparent change in distance between the targets was purely a perceptual effect. This being the case, the task could be fulfilled simply by making no compensatory adjustment in spite of what was seen. Accordingly, "apparent size" instructions were used to promote a spirit of cooperation.

The stimuli were adjusted so as to subtend a visual angle of $6 \mathrm{deg}$ at a distance of $5,10,20$, or $30 \mathrm{ft}$. The subject was asked to take note of the amount of separation and to hold it constant as instructed. The targets were set into motion, with the starting distance randomized over subjects. The initial direction of movement, i.e., either toward or away from the observer, was counterbalanced over subjects. The stimuli moved at the aforementioned rate of 6 in./ sec for five complete back-and-forth cycles or trials. That is to say, there were 10 adjustments for each distance, five with forward movement and five with backward. This was true as well for the 5- and $30-\mathrm{ft}$ distances, because the targets overshot these limits by $1 / 2$ in.

In Condition 2 the targets were presented statically at a distance of $5,10,20$, and $30 \mathrm{ft}$ in random order. They were always separated by $6 \mathrm{deg}$ of visual arc and served as the standard stimulus. The subject was requested to take note of how far apart the stimuli appeared to be. Then, upon turning to the right. the subject observed a duplicate stimulus arrangement (comparison stimulus) set at a fixed distance of $10 \mathrm{ft}$. By varying another control knob, the subject adjusted the comparison so that the separation between the stimuli appeared to be equal to that of the standard. (The adjustment of the comparison was recorded on the dynograph.) Ten such adjustments were made to each distance of the standard. "Apparent size" instructions were again given and the subject was requested to close his eyes between trials. Thus, size matches were obtained under static stimulus presentation. The order of the two conditions was counterbalanced over subjects.

Six males and four females participated. Ranging in age from 18 to 38 years, the mean age was 21.7 years. All were naive as to the purpose of the study.

\section{Results and Discussion}

The void between the stimuli was grossly overestimated in Condition 1. The mean judgments rendered were $154 \%, 143 \%, 119 \%$, and $107 \%$ of constancy for the 5-, 10-, 20-, and 30-ft distances, respectively. These differences were significant according to the Friedman two-way analysis of variance $\left(x r^{2}=29.43, \mathrm{df}=3, \mathrm{p}<.01\right)$. Subsequent Wilcoxon tests indicated that there was a reliable decrement in estimated linear extent from 5 to $10 \mathrm{ft}(\mathrm{t}=0, \mathrm{~N}=9$, $\mathrm{p}<.01), 10$ to $20 \mathrm{ft}(\mathrm{t}=0, \mathrm{~N}=10, \mathrm{p}<.01)$, and 20 to $30 \mathrm{ft}(\mathrm{t}=0, \mathrm{~N}=10, \mathrm{p}<.01)$.

It was felt that the inflated size estimates were an artifact of the procedure. Any tendency to overestimate size could not be offset hy reference to a constantly fixed standard. The subject's only point of reference was his immediately preceding judgment. Therefore. as the procedure continued and the subject forgot the extent of the void between the stimuli at their initial setting, the overestimations became progressively magnified. It is interesting to note, however, that as the target approached the judgments always increased in size as a function of decreasing distance. A close target was never judged to be smaller than it was at an immediately preceding distance. Similarly, movement away from the observer invariably resulted in a perceived collapse of the targets, as indicated by the compensatory adjustments. This was a universal finding which attested to the reliability of the adjustment data. Thus, disregarding the absolute magnitude of the above data, it can be readily seen that size deteriorated as a function of increasing distance.

The subjects' manual adjustments were in full accord with their naive phenomenal experience. Their reports were obtained after the experimental situation when they were permitted to view the moving targets with no compensatory adjustments required. The targets were seen clearly to collapse upon each other as they receded off into the distance and to depart from each other markedly as they approached the observer. In addition, the spheres themselves appeared to shrink and $\operatorname{dim}$ as a function of increasing distance. These effects were pronounced and occurred regardless of the type of critical attitude adopted. It was impossible to see that void between the stimuli remain constant. The combination of phenomenological and operant data show without question that a progressive departure from constancy was generated by dynamically increasing distance. Oddly enough, this regression toward visual angle was found with binocular viewing.

Unlike Condition 1, the static presentation of the stimuli (Condition 2) produced mean size matches that were $80 \%$. 78\%, 99\%, and $89 \%$ of constancy. These differences were significant according to the Friedman two-way analysis of variance $\left(\chi \mathrm{r}^{2}=13.8, \mathrm{df}=3\right.$, $\mathrm{p}<.01)$. Subsequent Wilcoxon tests indicated that constancy was approximated to a significantly greater extent when the standard was positioned at $20 \mathrm{ft}$, compared to the 5-, 10-, and 30-ft settings (in each case $t=3, N=10, p<.01$ ). The size matches for the 5 -, $10-$, and $30-\mathrm{ft}$ distance standards were essentially the same. In no instance was there evidence for a regression toward visual angle. Quite to the contrary, the $20-\mathrm{ft}$ standard elicited overconstancy judgments. Hence, typical constancy findings under binocular viewing were obtained with static stimulus presentation. Therefore, it may be concluded that movement inhibited the phenomenal experience of constancy.

\section{EXPERIMENT II}

The subjects responded as if they were viewing the 
targets monocularly in the dynamic condition of the last study. Accordingly, the present experiment was directed at assessing whether size estimations under dynamic and static presentation would approximate each other with monocular vision.

\section{Method}

The apparatus and procedure were the same as in the last experiment, except that the targets were now observed with the dominant eye only. Four males and six females participated. Ranging in age from 19 to 24 years, their mean age was 21.3 years. All were naive as to the purpose of the study.

\section{Results and Discussion}

In Condition 1 the mean estimates were 100\%, 96\%, $85 \%$, and $76 \%$ of constancy for the 5-, 10-, 20-, and 30-ft distances, respectively. These differences were significant according to the Friedman two-way analysis of variance $\left(\mathrm{xr}^{2}=29.43, \mathrm{df}=3, \mathrm{p}<.01\right)$. Subsequent Wilcoxon tests indicated that there was a reliable decrement in apparent size as the stimuli moved from 5 to $10 \mathrm{ft}$ away $(\mathrm{t}=0, \mathrm{~N}=9, \mathrm{p}<.01)$, as well as from 10 to 20 and 20 to $30 \mathrm{ft}$ (in each instance $t=0, N=10$, $\mathrm{p}<.01)$. Thus, the movement of stimuli back and forth into depth once again affected a reliable departure from constancy and a regression toward visual angle.

In Condition 2 the comparison was adjusted to the extent of $83 \%, 93 \%, 85 \%$, and $65 \%$ constancy for the 5-, 10-, 20-, and 30-ft settings of the standard. These differences were significant according to the Friedman test $\left(\chi \mathrm{r}^{2}=15.93, \mathrm{df}=3, \mathrm{p}<.01\right)$. The Wilcoxon test showed that, as the distance of the standard was increased from 5 to $10 \mathrm{ft}$, the size estimates grew significantly, so as to more accurately approximate constancy $(t=7, N=10, p<.05)$. While there was no essential change from 10 to $20 \mathrm{ft}$, there was a dramatic departure from constancy as the location of the standard was changed from 20 to $30 \mathrm{ft}(\mathrm{t}=0, \mathrm{~N}=10, \mathrm{p}<.01)$. The size matches at $30 \mathrm{ft}$ were substantially poorer than those at $5 \mathrm{ft}(\mathrm{t}=4, \mathrm{~N}=10, \mathrm{p}<.01)$, as well as at $10 \mathrm{ft}$ $(\mathrm{t}=1, \mathrm{~N}=10, \mathrm{p}<.01)$. Clearly, then, the data demonstrated that constancy was maintained with the standard positioned as far as $20 \mathrm{ft}$ away and that it finally broke down at the 30 -ft distance. Thus, it was apparent that the dynamic and static modes of presentation were not comparable even with monocular viewing. It was evident in comparing the two conditions that, while constancy was obtained over a modest distance when matching the size of a stationary stimulus, it did not hold at all for a moving target.
To integrate both studies, the size estimates of moving stimuli regressed toward visual angle under binocular and monocular observation. To the contrary, constancy was maintained for static presentation except when the targets were viewed monocularly at a far distance (i.e., $30 \mathrm{ft}$ ). Therefore, it may be concluded that movement inhibited phenomenal constancy.

The results were quite opposite to what was expected. Because the perceptual conditions were quite impoverished, there were few, if any, cues to distance available. It was reasoned that constancy should have been facilitated under dynamic viewing because of two critical cues introduced by virtue of movement. For one, the act of inspecting a single object displacing into the third dimension should have given rise to a sense of continuity, physical invariance, or phenomenal identity. Second, the movement of an object in depth results in a radial motion of the borders of that object which changes in its angular velocity directly as a function of distance. These changes in velocity could have served as an added cue to distance, thereby directly revealing the invariance between size and distance. To the contrary, however, it led to the inescapable sensation of expansion and contraction, or size change, rather than distance change. Accordingly, the radial motion produced by displacement into the third dimension seemed to interfere with phenomenal constancy. Constancy was obtained only in the absence of such intrusive effects, such as in the case of matching the size of stationary stimuli. Conceptually, then, the constancy phenomenon must be restricted to a limited number of conditions. It seems to be purely fictional as applied to a world of dynamic perception.

\section{REFERENCES}

Boring, E. G. The moon illusion. American Journal of Physics, $1943,2,55-60$.

Boring, E. G. Visual perception as invariance. Psychological Review, 1952, 59, 141-148.

Brosgole, L. An analysis of induced motion. Acta Psychologica, $1968,28,1.44$.

Gibson, J. J. The visual field and the visual world: A reply to Professor Boring. Psychological Review, 1952, 59, 149-151.

Holway, A. H., \& Boring, E. G. Determinants of apparent visual size with distance variant. American Journal of Psychology, 1941, 54, 21-37.

Koffka, K. Principles of Gestalt psychology. New York: Harcourt, Brace, 1935.

(Received for publication September 18, 1975.) 